\title{
Molecular Mechanisms of Hair Growth and Regeneration: Current Understanding and Novel Paradigms
}

\begin{abstract}
Khosrow Siamak Houschyar ${ }^{a}$ Mimi R. Borrellib Christian Tapking ${ }^{c, d}$
Daniel Popp $^{c, e}$ Behrus Puladi ${ }^{f}$ Mark Ooms $^{f}$ Malcolm P. Chelliah ${ }^{b}$

Susanne Reing ${ }^{g}$ Dominik Pförringer ${ }^{h}$ Dominik Thor ${ }^{i}$ Georg Reumuth $^{j}$

Christoph Wallner $^{a}$ Ludwik K. Branski ${ }^{c}$ Frank Siemers ${ }^{j}$ Gerrit Grieb $^{k}$

Marcus Lehnhardt ${ }^{\mathrm{a}}$ Amir S. Yazdi ${ }^{l}$ Zeshaan N. Maan ${ }^{\mathrm{b}}$ Dominik Duscher ${ }^{\mathrm{m}}$

aD Department of Plastic Surgery, BG University Hospital Bergmannsheil, Ruhr University Bochum, Bochum, Germany; ${ }^{b}$ Division of Plastic and Reconstructive Surgery, Department of Surgery, Stanford School of Medicine, Stanford, CA, USA; ' Department of Surgery, Shriners Hospitals for Children-Galveston, University of Texas Medical Branch, Galveston, TX, USA; ${ }^{d}$ Department of Hand, Plastic and Reconstructive Surgery, Burn Trauma Center,

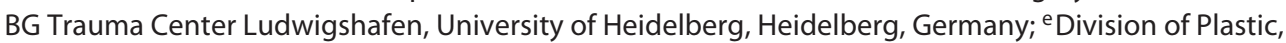
Aesthetic and Reconstructive Surgery, Department of Surgery, Medical University of Graz, Graz, Austria; fDepartment of Oral and Maxillofacial Surgery, University Hospital RWTH, Aachen, Germany; ${ }^{9}$ Department of

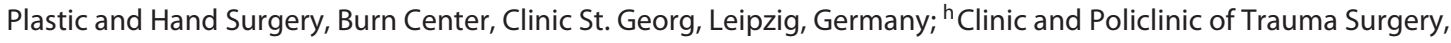
Klinikum Rechts der Isar, Technische Universität München, Munich, Germany; ${ }^{i}$ College of Pharmacy, University of

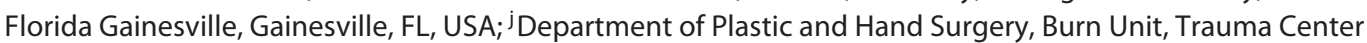
Bergmannstrost Halle, Halle, Germany; ${ }^{k}$ Department of Plastic Surgery and Hand Surgery,

Gemeinschaftskrankenhaus Havelhoehe, Teaching Hospital of the Charité Berlin, Berlin, Germany; 'Department of Dermatology and Allergology, University Hospital Aachen, Aachen, Germany; ${ }^{m}$ Department of Plastic Surgery and Hand Surgery, Technical University Munich, Munich, Germany
\end{abstract}

\section{Keywords}

Hair growth $\cdot$ Follicle $\cdot$ Regeneration $\cdot$ Wnt $\cdot \beta$-Catenin .

Hypoxia-inducible factor pathway $\cdot$ Stem cells

\section{Abstract \\ Hair is a defining feature of mammals and has critical func- tions, including protection, production of sebum, apocrine sweat and pheromones, social and sexual interactions, ther- moregulation, and provision of stem cells for skin homeosta- sis, regeneration, and repair. The hair follicle (HF) is consid-}

ered a "mini-organ," consisting of intricate and well-organized structures which originate from HF stem and progenitor cells. Dermal papilla cells are the main components of the mesenchymal compartments in the hair bulb and are instrumental in generating signals to regulate the behavior of neighboring epithelial cells during the hair cycle. Mesenchymal-epithelial interactions within the dermal papilla niche drive HF embryonic development as well as the postnatal hair growth and regeneration cycle. This review summarizes the current understanding of HF development, repair, and regeneration, with special focus on cell signaling karger@karger.com

(c) 2020 S. Karger AG, Basel

www.karger.com/drm

Karger
Dominik Duscher, MD, PhD

Division of Experimental Plastic Surgery, Department of Plastic and Hand Surgery Technical University Munich, Ismaninger Strasse 22

DE-81675 Munich (Germany)

dominik.duscher@mri.tum.de 
pathways governing these processes. In particular, we discuss emerging paradigms of molecular signaling governing the dermal papilla-epithelial cellular interactions during hair growth and maintenance and the recent progress made towards tissue engineering of human hair follicles.

(c) 2020 S. Karger AG, Basel

\section{Introduction}

The hair follicle (HF), considered a "mini-organ" and a signature of mammalian skin, is comprised of two main cells: dermal papilla cells (DPCs) and epithelial cells. The DPCs are derived from the mesenchyme, and the epithelial cells are derived from the surface epithelium. The HF undergoes continuous cycling throughout adult life and recapitulates embryonic growth as its own elements are regenerated with each hair cycle. Reciprocal dermal-epidermal interactions between the DPC and epithelial cells critically regulate hair growth and development [1]. During embryogenesis, the HF develops in three distinct stages: (1) induction, (2) organogenesis, and (3) cytodifferentiation [2]. These steps are coordinated by a number of signaling pathways [3] including the $\mathrm{Wnt} / \beta$-catenin, hedgehog, notch, and bone morphogenic protein (BMP) pathways [4]. These same pathways are also responsible for regulating postnatal HF cycling in conjunction with the hypoxia-inducible factor-1a (HIF-1 $\alpha$ ) pathway. Human and murine HFs share the same principal cell types and the same essential features of organization and function. While hair research in the mouse has long been both the foundation of our understanding of hair biology [5], recent work has provided insight into human HF biology, which has facilitated the development of novel therapies for skin disorders [6]. The human HF is the focus of this review.

\section{Embryological Development of Human Hair}

Human HF develops in embryonic life in four distinct stages, beginning in the ninth week of intrauterine life. The HF structure is preserved across multiple tissue types, including the nails, teeth, and most exocrine glands [7], and reciprocal interactions between the epidermal placode and the underlying dermal cells crucially determine HF formation [8]. An array of signaling pathways is thought to mediate this communication. Although many of the key pathways have not yet been identified, it is understood that Wnt, hedgehog, transforming growth factor- $\beta$ (TGF- $\beta$ )/BMP, fibroblast growth factor (FGF), and the various tumor necrosis factor (TNF) paracrine signaling factors have fundamental roles [9]. The mesenchyme initiates signaling which stimulates a thickening of the epidermis and formation of a hair placode [1]. Once established, the placode cells induce the mesenchymal cells to form a dermal condensate that ultimately forms the HF dermal papilla [10].

Signals from the dermal condensate then promote ingrowth of the epithelial cells down into the dermis [1]. Further reciprocal epithelial-mesenchymal signaling likely induce maturation and formation of the different HF lineages. These processes have been classically categorized into three phases: induction, organogenesis, cytodifferentiation [4].

The surrounding dermal cells conjugate around the placode and form a hair bud. The hair bud subsequently proliferates, lengthens, and invaginates into the dermis, forming the hair peg. Mesenchymal tissue then accumulates in the area, resulting in the hair bulb. Differentiation of the surrounding epithelial cells results in formation of the HF wall, hair epithelial sheath, and a small swelling that will eventually form the sebaceous gland. Proliferation and keratinization of central epithelial cells forms the hair cone. After the sebaceous gland differentiation and when the hair protrudes through the skin, the HF is complete [11]. HFs throughout the body develop at different rates, but by 21 weeks of fetal life, all areas of the body have at least one HF. The development of HF progresses in a cephalocaudal direction, and by the time there are long hairs on the face and scalp, many areas of the trunk and extremities have hairs within the cellular sheaths or hairs partially protruding through the epidermis [12].

The mechanisms determining HF fate are governed by local gradients of HF activators and inhibitors [13]. Wnt, Eda-A1, and noggin induce placode formation [14]. Signals which inhibit HF development, however, remain yet to be determined. Wnt activity within and around developing hair placodes is under tight control, which is important given its integral role in HF cycling [15] and the potential for skin tumor formation with overactive epidermal Wnt/ $\beta$-catenin signaling [16]. As in the "Turing model of reaction-diffusion systems," previously described in the context of feather development, extracellular secreted Wnt and Dickkopfs (Dkks) likely direct placode formation through a reaction-diffusion system. Small-molecular-weight Wnt inhibitor Dkk4, for example, easily diffuses and inhibits Wnt signaling in the interfollicular epidermis, whereas larger Wnt molecules tend to remain within the placode [17]. 
Table 1. The main phases of hair growth

\begin{tabular}{|c|c|}
\hline Stage & Key features \\
\hline Anagen & $\begin{array}{l}\text { Active growth phase } \\
\text { Early anagen: hair matrix forms new hair } \\
\text { Nourishment of HF from blood supply enables hair growth } \\
\text { Lasts } 2-6 \text { years }\end{array}$ \\
\hline Catagen & $\begin{array}{l}\text { Intermediate or "transition" phase } \\
\text { Deeper portion of the HF starts to collapse, HF detaches from nourishing blood supply } \\
\text { Lasts 1-2 weeks }\end{array}$ \\
\hline Telogen & $\begin{array}{l}\text { Resting phase } \\
\text { Remains of the hair bulk are inactive, papillary cells completely separate from HF } \\
\text { Lasts 5-6 weeks }\end{array}$ \\
\hline Exogen & $\begin{array}{l}\text { Shedding phase } \\
\text { Hairs at the end of their life fall out } \\
\text { Mainly coupled to early anagen but also occurs in telogen }\end{array}$ \\
\hline
\end{tabular}

HF, hair follicle. Reference: https://www.sciencedirect.com/science/article/pii/S0022202X15417737.

\section{Hair Follicle Cycling}

The HF of mammalian skin regularly cycles between involution and regeneration throughout postnatal life [18]. There are four main phases of the HF cycle: (1) anagen (growth), (2) catagen (regression), (3) telogen (rest), and (4) exogen (shedding) [7] (Fig. 1; Table 1). The duration of each phase varies by anatomical location, nutritional and hormonal status, age, and species [19]. In mice, for example, the first "test" hair shaft is generated relatively late at 17 days postpartum [20] and is consequently often misinterpreted as "first anagen" [4]. Scalp follicles undergo 10-30 cycles in a lifetime. The cycling of human HF is thought to be associated with the distribution of white adipose tissue which clusters around pilosebaceous units in structures called "dermal cones" [21].

\section{Anagen}

Anagen is the growth phase, and true anagen occurs 4 weeks after birth [22]. The stem cells present within the bulge region begin to proliferate at the onset of anagen to produce a new lower HF [23]. Human HF bulge cells are keratin 15 (K15) positive and express high levels of $\beta_{1^{-}}$ integrin [23]. The hair matrix transient amplifying cells, derived from epithelial HF stem cells in the bulge, also proliferate intensively and subsequently differentiate into distinct epithelial hair lineages [24]. For the remainder of anagen, and for catagen and telogen growth phases, the HF stem cells are otherwise extremely slow-cycling [23].
The anagen growth phase of human scalp hairs can last between 2 and 8 years [25].

\section{Catagen}

Catagen marks the period of rapid HF involution, where the entire lower two thirds of the HF rapidly degenerate over 2-3 weeks leaving only club hair surrounded by an epithelial cap (Fig. 1). This occurs mainly by apoptosis of dermal matrix, inner root sheath (IRS), and outer root sheath (ORS) keratinocytes. There is sparing of the bulge HF stem cells [26]. The end result is formation of an epithelial strand, a remnant of the HF, which functions to approximate the dermal papilla with the bulge [27]. In mice, the old hair shaft (club hair, now detached), normally remains in situ in the hair canal as the new hair emerges through the same orifice. In mice, the club hair may rest in the socket for several cycles and thus act to contribute to the density of the coat and leads to bulging of the ORS around the club [28].

\section{Telogen}

Telogen follows catagen, marks the resting phase of HF cycling, and involves the shedding or loss of hair (Fig. 1) [29]. Early in life, mice have highly coordinated HF cycling throughout the skin, but synchrony is lost with increasing age [7]. Humans, on the other hand, exhibit desynchronization of HF cycles shortly after birth [7]. Furthermore, the duration of telogen increases throughout development; there is slower HF turnover in aged animals [30] and in humans [31]. Although classi- 
Fig. 1. Hair development is a continuous cyclic process. All mature follicles go through a growth cycle consisting of four main phases: growth (anagen), regression (catagen), rest (telogen), and shedding (exogen).

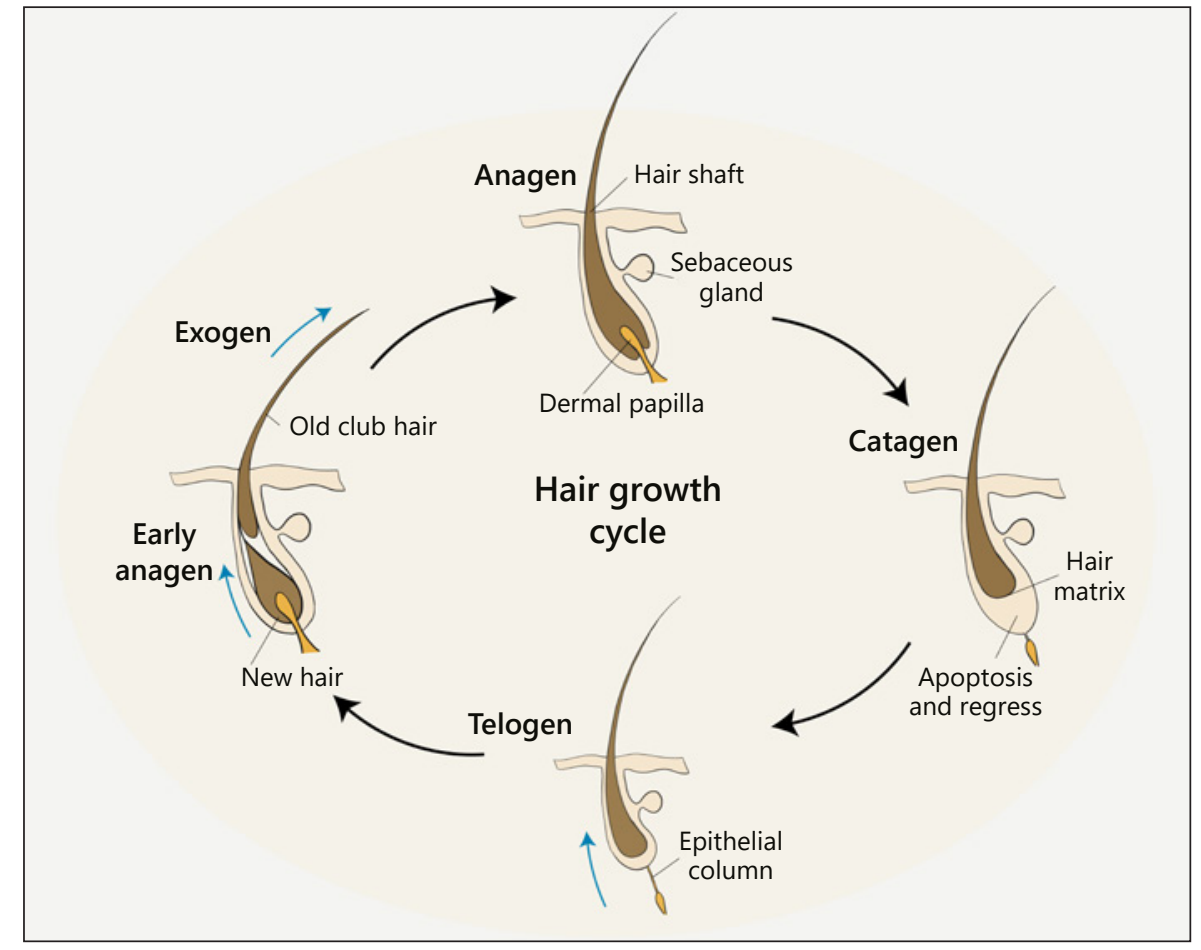

cally thought of as a stage of relative quiescence, telogen is now recognized to be an extremely active stage that is critical in controlling HF cycling [7]. The variety in hair length observed throughout the human body (e.g., eyelashes, torso, scalp) is due to the ratio between anagen and telogen phases. Scalp hair, for example, has a high anagen:telogen ratio resulting in long hair, but eyelashes and hair on the limbs spend less time in anagen and more time in telogen, resulting in shorter hair [32].

\section{Exogen}

While old hair shafts can be shed passively by mechanical forces, shedding in exogen is primarily an active process (Fig. 1) [33].

Human HFs transition through the cycles at different rates. On average human HFs cycle every 2-8 years, meaning at any one point roughly $86 \%$ of hairs are in anagen, $1 \%$ are in catagen, and the remaining $13 \%$ are in telogen [34].

\section{Hair Follicle Stem Cells}

The HF stem cells are located in the bulge region within the ORS [35]. During homeostasis, these bulge cells are slow cycling and quiescent in nature [36-38]. Like stem cells in other organs, they have a distinct biological makeup and persist throughout life [37]. Inflammation-induced damage to the bulge, and destruction of bulge cells, may produce permanent and cicatricial alopecia [39]. The keratin filament $\mathrm{K} 15$ has been used to prospectively isolate murine bulge stem cells to explore their gene expression profiles [40]. Expression of keratin filament K15 and $\mathrm{K} 19$, increased expression of CD200 and decreased expression of CD34, nestin, and connexin 43 are thought to mark the presence of human bulge epithelial stem cells [7].

The "bulge activation hypothesis" proposes that bulge stem cells maintain HF homeostasis through periodic cycling [41]. Proliferation of the bulge stem cells marks the initiation of anagen, resulting in daughter cells from asymmetric division. The stem cell progeny cells migrate to the base of the follicle and become highly proliferative "transiently activated matrix cells" capable of giving rise to all cell lineages of the mature HF [42]. Following injury, HF stem cells adopt differentiation programs that permit repair of injured sebaceous glands and the interfollicular epidermis [43]. Labeling and transplantation studies have suggested that HF stem cells give rise to keratinocytes, melanocytes, mesenchymal, and neural stem cells throughout life [8]. 


\section{Mechanisms of Hair Follicle Cycling}

Molecular mechanisms mediating HF cycling remain poorly understood. Work in mice has provided the foundation of our understanding regarding the key regulators [44], and increasingly the pathways regulating hair growth in humans are being identified:

\section{Anagen}

Gene expression profiling in mice and humans has identified many pathways finetune the balance between stem cell quiescence and maintenance [45]. Induction of anagen is largely dependent on the interplay between Wnt, activin/BMP, and TGF- $\beta$ /BMP signaling in human and mouse bulge cells [46], as well as FGF, and noggin, and sonic hedgehog (Shh) antagonists. Anagen onset is marked by an elevation in Wnts and stabilization of $\beta$-catenin, BMP inhibition by BMP antagonists [47], and increased levels of c-myc, and Runx1 [48] within HF bulge cells, leading to stem cell activation $[49,50]$. Mice lacking BMPR1a, have HF stem cells that are continuously activated and start proliferating aberrantly, resulting in the eventual loss of slow cycling cells in these mice [51]. As expected, these mice demonstrate increased and aberrant levels of the transcription factor lymphoid enhancer binding factor-1 (Lef-1) and stabilized $\beta$-catenin in the stem cell niche. In contrast, ablation of Wnt signaling in the HF bulge reduces the potency of stem cells and shifts the balance from hair growth to premature differentiation. Although there are similarities between mouse and human HF, there are also important structural and/ or biological differences between human and mouse bulge ORS. Only humans are observed to upregulate expression of DIO2 and ANGPTL2 [52, 53], and expression of latent TGF- $\beta$ binding protein 2 , FGF18, and, importantly, CD34 are also divergent between mice and humans [6].

Maintenance of anagen, in contrast, is controlled by insulin-like growth factor-1, hepatocyte growth factor, and vascular endothelial growth factor (VEGF) [54]. As anagen progresses, the bulge reverts to a Wnt-inhibited state [55], and Wnt inhibition by TCF3, Wnt inhibitory factor 1 and Dkks (e.g., Dkk3) and the calcium-dependent transcription factor NFATc1 [56] maintain bulge stem cells in a quiescent state [7]. BMP signaling also serves to prevent Wnt pathway activation and maintains HF stem cells in quiescence [57]. Knockdown studies of organ-cultured human scalp HFs reveal that P-cadherin is needed for anagen maintenance by regulating canonical Wnt signaling and suppressing TGF- $\beta_{2}$ [58].
As the epithelial HF stem cells re-enter quiescence, the daughter bulge cells migrate away from the dermal papilla [59]. Wnt signaling also specifies the differentiated cell fates in the anagen follicle [55]. Evidence for this is supported by the finding of increased expression of Wnt activators and decreased expression of Wnt inhibitors (e.g., Srfp1, Dab2, and TCF3) in nonbulge keratinocytes compared to bulge stem cells in mouse and human skin [60]. The transient amplifying cells (the stem cell progeny) maintain active Wnt signaling and concomitant stabilization of $\beta$-catenin throughout anagen $[61,62]$. Precortical hair matrix cells cease proliferating and undergo differentiation into various terminal HF epithelial cell lineages [7, 63]. The molecules involved in ORS formation include BMPs, GATA3 and Cutl1, whereas IRS formation involves Shh and Sox9. Hair shaft development and expression of hair shaft keratins is under control of $\mathrm{Wnt} / \beta$-catenin, BMPs, notch, vitamin D receptor (VDR) and Foxn1. TCF3 operates as a general inhibitor of all epithelial lineages [7].

\section{Catagen}

The anagen-to-catagen transition involves crosstalk between the downstream effectors of TNF- $\alpha$ signaling and K17 [64], VDR, the transcriptional repressor hairless, and the retinoic acid receptor [65]. Hairless interacts with VDR to regulate transcription, and mice deficient of either regulators have HFs which form epithelial sacs and dermal cysts upon entering catagen [66]; this disrupts the essential interaction between HF stem cells and the inductive HF mesenchyme [8]. FGF-5 is a potent growth factor which stimulates the onset of catagen [4]. Evidence supporting the role of FGF-5 comes from FGF-5-deficient mice who exhibit prolonged anagen and an angora phenotype (abnormally long body hair coat) [67]. FGF-5 is a critical regulator of human hair growth, and a recent study showed how mutations to FGF5 can lead to familial trichomegaly, or extreme eyelash growth [68]. Other factors also act in a synergistic manner to promote catagen onset including TGF- $\beta_{1}$, interleukin- $1 \beta$, neurotrophins 3 and 4 , bone-derived neurotrophic factor, BMP2 and BMP4, and TNF- $\alpha$ [7]. Treatment of human HF cells with all-transretinoic acid induces a catagen-like stage in part via upregulation of TGF- $\beta_{2}$ in the dermal papillary cells [69].

\section{Telogen}

Recent work in mice has divided telogen into: (1) the "refractory phase," where HFs are resistant to growth stimuli and have upregulated BMP2/4, and (2) the "competent" phase during which HF bulge stem cells are extremely sensitive to anagen-inducing factors, BMP signal- 


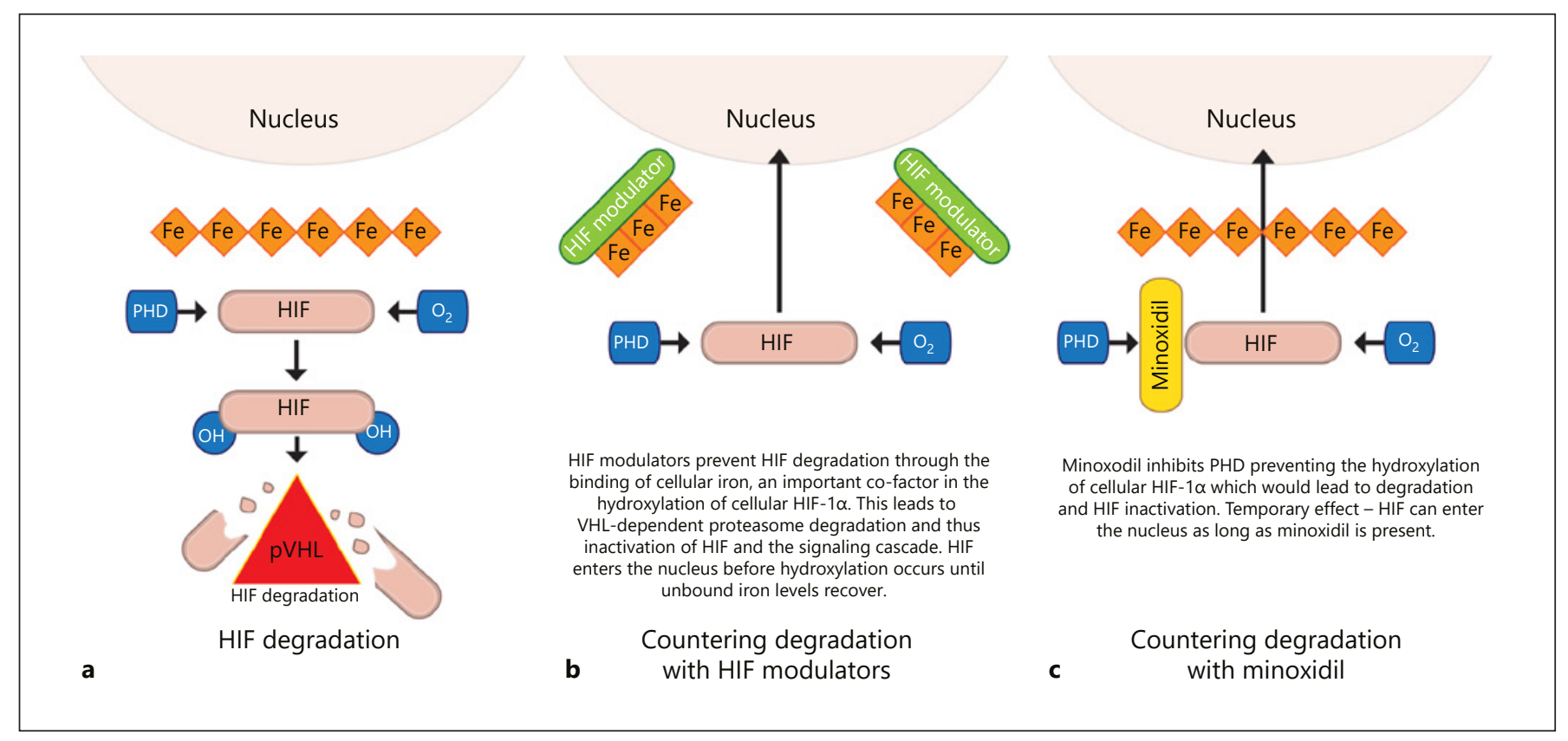

Fig. 2. Hypoxia-inducible factor (HIF) pathway regulation. a HIF hydroxylation occurs by prolylhydroxylase (PHD), followed by ubiquitylation by von Hippel-Lindau tumor suppressor protein (pVHL), which facilitates enzymatic degradation of HIF. b Truncated HIF breakdown pathway in the presence of HIF-modulating iron chelators, allowing HIF to remain intact and free to dimerize for downstream HIF pathway activation. c Prolylhydroxylase (PHD) is temporarily inhibited by minoxidil.

ing is diminished, and $\mathrm{Wnt} / \beta$-catenin signaling increases $[70,71]$. Of note, the estrogen receptor is appreciably upregulated throughout telogen [46]. This extrafollicular system and intrafollicular "hair cycle clock" must interact to ensure regulation of individual HF cycles, and this may relate to the observation of cyclical changes of BMP2 and BMP4 expression of extrafollicular skin, especially in subcutaneous adipocytes [72]. As the dermal papilla rests immediately below the bulge in telogen the bulge stem and dermal papilla cells can interact [73] and help coordinate stem cell activation and initiation of a new HF cycle [73]. Once a critical concentration of stem cell activators has been achieved, anagen begins again [61].

Many of the genes controlling epithelial HF stem cell activity and HF cycling have been identified. Future work involving mouse genetics and further HF cycle profiling will continue to elucidate the enigmatic "hair cycle clock" [74].

\section{Hair Follicles and Regenerative Medicine}

Hair loss is common and occurs in a variety of physiological states associated with hormonal imbalance, age, autoimmune conditions, medications, and genetics [75].
Damaged or destroyed hair stem cells are thought to be the reason underlying hair loss across these different situations. While scarring alopecia is thought to be due to the depletion of stem cells, balding is associated with maintaining of stem cells and loss of the progenitor cells [76]. While some progress has been made towards treating alopecia with autologous hair transplantation or drugs, to date most efforts have been unable to effectively achieve sufficient numbers of hair [77]. There has been some success with cotransplantation of DPCs and epithelium-derived follicular stem cells, consistent with the importance of reciprocal interactions between these stem cells for HF morphogenesis and hair cycling [78, 79]. The DPCs are believed to provide the necessary signals to the follicular epithelial stem cells to direct their differentiation and ultimately specify their shape, size, and pigmentation of resultant hair [8]. In culture, expansion eventually exhausts this proliferative and regenerative capacity [80]. The addition of certain growth factors can help increase hair generation efficiency, and molecules that have shown promise to date are FGF-2 [81], Wnt [82], and BMP [83]. Culture of DPCs in aggregate can promote the maintenance of important DPC-specific markers, and transplantation of HF germ cells com- 
prised of mesenchymal and epithelial cells that had been integrated in 3-dimensional cultures resulted in successful HF regeneration in mice [84]. While successful, this approach requires generation of a large number of HF germ cells which can be labor-intensive. Recent work is focused on improving the efficiency of methods to generate sufficient numbers of robust stem cells for hair regenerative medicine [85].

\section{Hair Follicles in Cutaneous Injury}

HF development bears resemblance to wound healing in that it requires a highly coordinated interplay between tissue regeneration, cell growth, and cell migration. HIF$1 a$ drives neovascularization and production of collagen and elastin during wound healing [86]. Stimulating the HIF pathway can significantly enhance both tissue regeneration and hair growth, suggesting human HF stem/progenitor cells are reactive to hypoxia (Fig. 2) [87-92]. Of note, minoxidil is a hair growth-stimulating agent, which when topically applied to the scalp, inhibits the HIF-degrading enzyme prolylhydroxylase, demonstrating a positive pharmacological effect on hair growth through activation of the angiogenic HIF-1-VEGF axis [90]. These findings suggest further research into HIF-modulating agents may unlock novel hair growth-stimulating therapeutics.

Work in mice suggests that, following cutaneous injury, Shh levels increase, with activation of the hedgehog pathway, restoring a regenerative dermal niche (dermal papilla), both sufficient and necessary for HF neogenesis [93]. Shh overexpression in the epidermis or constitutive smoothened dermal activation drives extensive HF neogenesis in wounds that would otherwise heal by scarring, suggesting Shh signal activation in Wnt-responsive cells promotes wound regeneration. TGF- $\beta$ and nerve growth factor families have opposing functions during HF development and cycling; both function to promote HF development, but also stimulate catagen in mature HF [94]. In addition, VDR, hairless, and notch are dispensable for HF development, but are critical for the induction of anagen in postnatal skin [95].

\section{Conclusions and Future Directions}

This review summarizes the current understanding of signaling pathways essential in governing HF development and cycling. The signaling cascades and crosstalk responsible for induction of HF development and morphogenesis, and the molecular differences governing fetal HF induction and development, compared to postnatal HF cycling, require further elucidation. From a clinical perspective, the key challenge will be to translate insights from HF biology into treatments for disorders such as androgenetic alopecia, telogen effluvium, alopecia areata, and hirsutism as well as applications for wound healing and tissue regeneration, including de novo induction of HFs in adult human skin. Although not discussed in depth here, it should be recognized that the proliferative character and long lifespan of HF stem cells puts them at risk of accumulating and retaining genetic mutations, which may precipitate tumor formation with time. The $\mathrm{HF}$ and its surrounding mesenchyme are recognized as potent sources for multipotent stem cell populations, raising hopes that stem cells associated with adult human HFs might soon become exploitable for use in regenerative medicine. Beyond the topics covered in this review, emerging areas in hair research - for example, understanding the immune privilege of the HF bulb and bulge as well as the complex (neuro-)endocrine activities of the $\mathrm{HF}$ - may revolutionize our understanding of HF biology in the near future.

\section{Key Message}

This review summarizes recent progress in understanding of the molecular mechanisms regulating hair follicle formation.

\section{Statement of Ethics}

Ethical approval was not required for this study.

\section{Disclosure Statement}

D.D. is a cofounder of, and has equity positions in, Tomorrowlabs $\mathrm{GmbH}$, a commercial-stage biotech company that produces products based on HIF-stimulating factor technology. The other authors have no conflicts of interest to declare. The authors listed expressly wrote the content of this article. No ghostwriters were used to write this article.

\section{Author Contributions}

K.S.H. conceived of the article, and the authors K.S.H., M.R.B., C.T., D.P., B.P., M.O., M.P.C., S.R., D.P., D.T., G.R., C.W., L.K.B., F.S., G.G., M.L., A.S.Y., Z.N.M., and D.D. made equal contributions to its written content. 


\section{References}

1 Hardy MH. The secret life of the hair follicle. Trends Genet. 1992 Feb;8(2):55-61.

2 Schmidt-Ullrich R, Paus R. Molecular principles of hair follicle induction and morphogenesis. BioEssays. 2005 Mar;27(3):247-61.

3 Millar SE. Molecular mechanisms regulating hair follicle development. J Invest Dermatol. 2002 Feb;118(2):216-25.

4 Rishikaysh P, Dev K, Diaz D, Qureshi WM, Filip S, Mokry J. Signaling involved in hair follicle morphogenesis and development. Int J Mol Sci. 2014 Jan;15(1):1647-70.

5 Oh JW, Kloepper J, Langan EA, Kim Y, Yeo J, Kim MJ, et al. A guide to studying human hair follicle cycling in vivo. J Invest Dermatol. 2016 Jan;136(1):34-44.

6 Ohyama M, Terunuma A, Tock CL, Radonovich MF, Pise-Masison CA, Hopping $\mathrm{SB}$, et al. Characterization and isolation of stem cell-enriched human hair follicle bulge cells. J Clin Invest. 2006 Jan;116(1):249-60.

7 Schneider MR, Schmidt-Ullrich R, Paus R. The hair follicle as a dynamic miniorgan. Curr Biol. 2009 Feb;19(3):R132-42.

8 Yang CC, Cotsarelis G. Review of hair follicle dermal cells. J Dermatol Sci. 2010 Jan; 57(1):2-11.

9 Perrimon N, Pitsouli C, Shilo BZ. Signaling mechanisms controlling cell fate and embryonic patterning. Cold Spring Harb Perspect Biol. 2012 Aug;4(8):a005975.

10 Woo WM, Zhen HH, Oro AE. Shh maintains dermal papilla identity and hair morphogenesis via a Noggin-Shh regulatory loop. Genes Dev. 2012 Jun;26(11):1235-46.

11 Grubbs H, Morrison M. Embryology, hair [Internet]. Treasure Island: StatPearls Publishing; 2018.

12 Holbrook KA, Odland GF. Structure of the human fetal hair canal and initial hair eruption. J Invest Dermatol. 1978 Dec;71(6) 385-90.

13 Li C, Pearson A, McMahon C. Morphogenetic mechanisms in the cyclic regeneration of hair follicles and deer antlers from stem cells. BioMed Res Int. 2013;2013:643601.

14 Stark J, Andl T, Millar SE. Hairy math: insights into hair-follicle spacing and orientation. Cell. 2007 Jan;128(1):17-20.

15 Jansson L, Kim GS, Cheng AG. Making sense of Wnt signaling-linking hair cell regeneration to development. Front Cell Neurosci. 2015 Mar;9:66.

16 Blagodatski A, Poteryaev D, Katanaev VL. Targeting the Wnt pathways for therapies. Mol Cell Ther. 2014 Sep;2(1):28.

17 Bazzi H, Fantauzzo KA, Richardson GD, Jahoda CA, Christiano AM. The Wnt inhibitor, Dickkopf 4, is induced by canonical Wnt signaling during ectodermal appendage morphogenesis. Dev Biol. 2007 May;305(2): 498-507.
18 Plikus MV, Chuong CM. Complex hair cycle domain patterns and regenerative hair waves in living rodents. J Invest Dermatol. 2008 May; 128(5):1071-80.

19 Tobin DJ. Aging of the hair follicle pigmentation system. Int J Trichology. 2009 Jul; $1(2): 83-93$

20 Mesler AL, Veniaminova NA, Lull MV, Wong SY. Hair Follicle Terminal Differentiation Is Orchestrated by Distinct Early and Late Matrix Progenitors. Cell Rep. 2017 Apr; 19(4):809-21.

21 Kruglikov IL, Scherer PE. Dermal adipocytes and hair cycling: is spatial heterogeneity a characteristic feature of the dermal adipose tissue depot? Exp Dermatol. 2016 Apr; 25(4):258-62.

22 Geyfman M, Plikus MV, Treffeisen E, Andersen B, Paus R. Resting no more: re-defining telogen, the maintenance stage of the hair growth cycle. Biol Rev Camb Philos Soc. 2015 Nov;90(4):1179-96.

23 Lyle S, et al. Human hair follicle bulge cells are biochemically distinct and possess an epithelial stem cell phenotype. J Investig Dermatol Symp Proc. 1999 Dec;4(3):296301.

24 Mistriotis P, Andreadis ST. Hair follicle: a novel source of multipotent stem cells for tissue engineering and regenerative medicine. Tissue Eng Part B Rev. 2013 Aug;19(4): 265-78.

25 Roh C, Tao Q, Photopoulos C, Lyle S. In vitro differences between keratinocyte stem cells and transit-amplifying cells of the human hair follicle. J Invest Dermatol. 2005 Dec;125(6):1099-105.

26 Martel JL, Badri T. Anatomy, hair follicle. Treasure Island: StatPearls Publishing; 2018.

27 Hsu YC, Pasolli HA, Fuchs E. Dynamics between stem cells, niche, and progeny in the hair follicle. Cell. 2011 Jan;144(1):92-105.

28 Plikus MV. New activators and inhibitors in the hair cycle clock: targeting stem cells state of competence. J Invest Dermatol. 2012 May;132(5):1321-4.

29 Burg D, Yamamoto M, Namekata M, Haklani J, Koike K, Halasz M. Promotion of anagen, increased hair density and reduction of hair fall in a clinical setting following identification of FGF5-inhibiting compounds via a novel 2-stage process. Clin Cosmet Investig Dermatol. $2017 \mathrm{Feb} ; 10: 71-85$.

30 Rodriguez CN, Nguyen H. Identifying quiescent stem cells in hair follicles. Methods Mol Biol. 2018;1686:137-47.

31 Higgins CA, Westgate GE, Jahoda CA. From telogen to exogen: mechanisms underlying formation and subsequent loss of the hair club fiber. J Invest Dermatol. 2009 Sep; 129(9):2100-8
32 Wang K, Li M, Hakonarson H. ANNOVAR: functional annotation of genetic variants from high-throughput sequencing data. $\mathrm{Nu}$ cleic Acids Res. 2010 Sep;38(16):e164-164.

33 Erdoğan B. Anatomy and physiology of hair. Hair and scalp disorders. IntechOpen; 2017. Available from: https://doi.org/10.5772/ 67269.

34 Harrison S, Sinclair R. Telogen effluvium Clin Exp Dermatol. 2002 Jul;27(5):389-5.

35 Soteriou D, et al. Isolating hair follicle stem cells and epidermal keratinocytes from dorsal mouse skin. J Vis Exp. 2016;110:53931.

36 Cotsarelis G, Sun TT, Lavker RM. Label-retaining cells reside in the bulge area of pilosebaceous unit: implications for follicular stem cells, hair cycle, and skin carcinogenesis. Cell. 1990 Jun;61(7):1329-37.

37 Lyle S, Christofidou-Solomidou M, Liu Y, Elder DE, Albelda S, Cotsarelis G. The C8/144B monoclonal antibody recognizes cytokeratin 15 and defines the location of human hair follicle stem cells. J Cell Sci. 1998 Nov;111(Pt 21):3179-88.

38 Oshima H, Rochat A, Kedzia C, Kobayashi $\mathrm{K}$, Barrandon Y. Morphogenesis and renewal of hair follicles from adult multipotent stem cells. Cell. 2001 Jan;104(2):233-45.

39 Harries MJ, Paus R. The pathogenesis of primary cicatricial alopecias. Am J Pathol. 2010 Nov;177(5):2152-62.

40 Bose A, Teh MT, Mackenzie IC, Waseem A Keratin k15 as a biomarker of epidermal stem cells. Int J Mol Sci. 2013 Sep;14(10): 19385-98.

41 Rompolas P, Greco V. Stem cell dynamics in the hair follicle niche. Semin Cell Dev Biol. 2014 Jan-Feb;25-26:34-42.

42 Myung P, Ito M. Dissecting the bulge in hair regeneration. J Clin Invest. $2012 \mathrm{Feb} ; 122(2)$ : 448-54.

43 Houschyar KS, Momeni A, Pyles MN, Maan ZN, Whittam AJ, Siemers F. Wnt signaling induces epithelial differentiation during cutaneous wound healing. Organogenesis. 2015;11(3):95-104.

44 Nakamura M, Schneider MR, Schmidt-Ullrich R, Paus R. Mutant laboratory mice with abnormalities in hair follicle morphogenesis, cycling, and/or structure: an update. J Dermatol Sci. 2013 Jan;69(1):6-29.

45 Leishman E, Howard JM, Garcia GE, Miao Q, Ku AT, Dekker JD, et al. Foxp1 maintains hair follicle stem cell quiescence through regulation of Fgf18. Development. 2013 Sep; 140(18):3809-18.

46 Ohnemus U, Uenalan M, Conrad F, Handjiski B, Mecklenburg L, Nakamura M, et al. Hair cycle control by estrogens: catagen induction via estrogen receptor (ER)-alpha is checked by ER beta signaling. Endocrinology. 2005 Mar;146(3):1214-25. 
47 Närhi K, Järvinen E, Birchmeier W, Taketo MM, Mikkola ML, Thesleff I. Sustained epithelial beta-catenin activity induces precocious hair development but disrupts hair follicle down-growth and hair shaft formation. Development. 2008 Mar;135(6):101928.

48 Kandyba E, Kobielak K. Wnt7b is an important intrinsic regulator of hair follicle stem cell homeostasis and hair follicle cycling. Stem Cells. 2014 Apr;32(4):886-901.

49 Lien WH, Polak L, Lin M, Lay K, Zheng D, Fuchs E. In vivo transcriptional governance of hair follicle stem cells by canonical Wnt regulators. Nat Cell Biol. 2014 Feb;16(2): 179-90.

50 Sethi JK, Vidal-Puig A. Wnt signalling and the control of cellular metabolism. Biochem J. 2010 Mar;427(1):1-17.

51 Kobielak K, Stokes N, de la Cruz J, Polak L, Fuchs E. Loss of a quiescent niche but not follicle stem cells in the absence of bone morphogenetic protein signaling. Proc Natl Acad Sci USA. 2007 Jun;104(24):10063-8.

52 Tumbar T, Guasch G, Greco V, Blanpain C, Lowry WE, Rendl M, et al. Defining the epithelial stem cell niche in skin. Science. 2004 Jan;303(5656):359-63.

53 Morris RJ, Liu Y, Marles L, Yang Z, Trempus C, Li S, et al. Capturing and profiling adult hair follicle stem cells. Nat Biotechnol. 2004 Apr;22(4):411-7.

54 Rajendran RL, Gangadaran P, Bak SS, Oh JM, Kalimuthu S, Lee HW, et al. Extracellular vesicles derived from MSCs activates dermal papilla cell in vitro and promotes hair follicle conversion from telogen to anagen in mice. Sci Rep. 2017 Nov;7(1):15560.

55 Blanpain C, Fuchs E. Epidermal stem cells of the skin. Annu Rev Cell Dev Biol. 2006; 22(1):339-73.

56 Horsley V, Aliprantis AO, Polak L, Glimcher LH, Fuchs E. NFATc1 balances quiescence and proliferation of skin stem cells. Cell. 2008 Jan;132(2):299-310.

57 Kandyba E, Leung Y, Chen YB, Widelitz R, Chuong CM, Kobielak K. Competitive balance of intrabulge BMP/Wnt signaling reveals a robust gene network ruling stem cell homeostasis and cyclic activation. Proc Natl Acad Sci USA. 2013 Jan;110(4):1351-6.

58 Samuelov L, Sprecher E, Tsuruta D, Bíró T, Kloepper JE, Paus R. P-cadherin regulates human hair growth and cycling via canonical Wnt signaling and transforming growth factor- $\beta 2$. J Invest Dermatol. 2012 Oct; 132(10):2332-41.

59 Woo WM, Oro AE. Snapshot: hair follicle stem cells. Cell. 2011;146(2):334.e2.

60 Sokol SY. Maintaining embryonic stem cell pluripotency with Wnt signaling. Development. 2011 Oct;138(20):4341-50

61 Greco V, Chen T, Rendl M, Schober M, Pasolli HA, Stokes N, et al. A two-step mechanism for stem cell activation during hair regeneration. Cell Stem Cell. 2009 Feb;4(2): 155-69.
62 Enshell-Seijffers D, Lindon C, Kashiwagi M, Morgan BA. beta-catenin activity in the dermal papilla regulates morphogenesis and regeneration of hair. Dev Cell. 2010 Apr;18(4): 633-42.

63 Nowak JA, Polak L, Pasolli HA, Fuchs E. Hair follicle stem cells are specified and function in early skin morphogenesis. Cell Stem Cell. 2008 Jul;3(1):33-43.

$64 \mathrm{Wu} \mathrm{H}$, Che X, Zheng Q, Wu A, Pan K, Shao A, et al. Caspases: a molecular switch node in the crosstalk between autophagy and apoptosis. Int J Biol Sci. 2014 Sep;10(9): 1072-83.

65 Chuma M, Endo-Umeda K, Shimba S, Yamada S, Makishima M. Hairless modulates ligand-dependent activation of the vitamin $\mathrm{D}$ receptor-retinoid $\mathrm{X}$ receptor heterodimer. Biol Pharm Bull. 2012;35(4):582-7.

66 Teichert A, Elalieh H, Bikle D. Disruption of the hedgehog signaling pathway contributes to the hair follicle cycling deficiency in $\mathrm{Vdr}$ knockout mice. J Cell Physiol. 2010 Nov: 225(2):482-9.

67 Hébert JM, Rosenquist T, Götz J, Martin GR. FGF5 as a regulator of the hair growth cycle: evidence from targeted and spontaneous mutations. Cell. 1994 Sep;78(6):101725.

68 Higgins CA, Petukhova L, Harel S, Ho YY, Drill E, Shapiro L, et al. FGF5 is a crucial regulator of hair length in humans. Proc Natl Acad Sci USA. 2014 Jul;111(29):1064853.

69 Foitzik K, Spexard T, Nakamura M, Halsner U, Paus R. Towards dissecting the pathogenesis of retinoid-induced hair loss: alltrans retinoic acid induces premature hair follicle regression (catagen) by upregulation of transforming growth factor- $\beta 2$ in the dermal papilla. J Invest Dermatol. 2005 Jun; 124(6):1119-26

70 Plikus MV, Mayer JA, de la Cruz D, Baker RE, Maini PK, Maxson R, et al. Cyclic dermal BMP signalling regulates stem cell activation during hair regeneration. Nature. 2008 Jan;451(7176):340-4.

71 Castellana D, Paus R, Perez-Moreno M. Macrophages contribute to the cyclic activation of adult hair follicle stem cells. PLoS Biol. 2014 Dec;12(12):e1002002.

72 Kim M, Choe S. BMPs and their clinical potentials. BMB Rep. 2011 Oct;44(10):619-34.

73 Morgan BA. The dermal papilla: an instructive niche for epithelial stem and progenitor cells in development and regeneration of the hair follicle. Cold Spring Harb Perspect Med. 2014 Jul;4(7):a015180.

74 Mecklenburg L, Tobin DJ, Cirlan MV, Craciun C, Paus R. Premature termination of hair follicle morphogenesis and accelerated hair follicle cycling in Iasi congenital atrichia (fzica) mice points to fuzzy as a key element of hair cycle control. Exp Dermatol. 2005 Aug;14(8):561-70.
75 Chueh SC, Lin SJ, Chen CC, Lei M, Wang LM, Widelitz R, et al. Therapeutic strategy for hair regeneration: hair cycle activation, niche environment modulation, wound-induced follicle neogenesis, and stem cell engineering. Expert Opin Biol Ther. 2013 Mar; 13(3):377-91.

76 Garza LA, Yang CC, Zhao T, Blatt HB, Lee $\mathrm{M}, \mathrm{He} \mathrm{H}$, et al. Bald scalp in men with androgenetic alopecia retains hair follicle stem cells but lacks CD200-rich and CD34-positive hair follicle progenitor cells. J Clin Invest. $2011 \mathrm{Feb} ; 121(2): 613-22$

77 Stenn KS, Cotsarelis G. Bioengineering the hair follicle: fringe benefits of stem cell technology. Curr Opin Biotechnol. 2005 Oct; 16(5):493-7.

78 Steinberg MS, Takeichi M. Experimental specification of cell sorting, tissue spreading, and specific spatial patterning by quantitative differences in cadherin expression. Proc Natl Acad Sci USA. 1994 Jan;91(1): 206-9.

79 Reynolds AJ, Jahoda CA. Cultured dermal papilla cells induce follicle formation and hair growth by transdifferentiation of an adult epidermis. Development. 1992 Jun; 115(2):587-93.

80 Inoue $\mathrm{K}$, Kato $\mathrm{H}$, Sato T, Osada A, Aoi N, Suga H, et al. Evaluation of animal models for the hair-inducing capacity of cultured human dermal papilla cells. Cells Tissues Organs. 2009;190(2):102-10.

81 Osada A, Iwabuchi T, Kishimoto J, Hamazaki TS, Okochi H. Long-term culture of mouse vibrissal dermal papilla cells and de novo hair follicle induction. Tissue Eng. 2007 May;13(5):975-82.

82 Kishimoto J, Burgeson RE, Morgan BA. Wnt signaling maintains the hair-inducing activity of the dermal papilla. Genes Dev. 2000 May;14(10):1181-5.

83 Rendl M, Polak L, Fuchs E. BMP signaling in dermal papilla cells is required for their hair follicle-inductive properties. Genes Dev. 2008 Feb;22(4):543-57.

84 Toyoshima KE, Asakawa K, Ishibashi N, Toki H, Ogawa M, Hasegawa T, et al. Fully functional hair follicle regeneration through the rearrangement of stem cells and their niches. Nat Commun. 2012 Apr;3(1):784.

85 Kageyama T, Yan L, Shimizu A, Maruo S, Fukuda J. Preparation of hair beads and hair follicle germs for regenerative medicine. Biomaterials. 2019 Aug;212:55-63.

86 Pagani A, Aitzetmüller MM, Brett EA, König V, Wenny R, Thor D, et al. Skin Rejuvenation through HIF-1a Modulation. Plast Reconstr Surg. 2018 Apr;141(4):600e7 e.

87 Rathman-Josserand M, Genty G, Lecardonnel J, Chabane S, Cousson A, François Michelet J, et al. Human hair follicle stem/progenitor cells express hypoxia markers. J Invest Dermatol. 2013 Aug;133(8):2094-7. 
88 Rezvani HR, Ali N, Nissen LJ, Harfouche G, de Verneuil H, Taïeb A, et al. HIF-1 1 in epidermis: oxygen sensing, cutaneous angiogenesis, cancer, and non-cancer disorders. J Invest Dermatol. 2011 Sep;131(9):1793805.

89 Yum S, Jeong S, Kim D, Lee S, Kim W, Yoo JW, et al. Minoxidil Induction of VEGF Is Mediated by Inhibition of HIF-Prolyl Hydroxylase. Int J Mol Sci. 2017 Dec;19(1):E53.
90 Duscher D, Januszyk M, Maan ZN, Whittam AJ, Hu MS, Walmsley GG, et al. Comparison of the Hydroxylase Inhibitor Dimethyloxalylglycine and the Iron Chelator Deferoxamine in Diabetic and Aged Wound Healing. Plast Reconstr Surg. 2017 Mar; 139(3):695e-706e.

91 Hong WX, Hu MS, Esquivel M, Liang GY, Rennert RC, McArdle A, et al. The Role of Hypoxia-Inducible Factor in Wound Healing. Adv Wound Care (New Rochelle). 2014 May;3(5):390-9.

92 Duscher D, Neofytou E, Wong VW, Maan $\mathrm{ZN}$, Rennert $\mathrm{RC}$, Inayathullah $\mathrm{M}$, et al Transdermal deferoxamine prevents pressure-induced diabetic ulcers. Proc Natl Acad Sci USA. 2015 Jan;112(1):94-9.
93 Lim CH, Sun Q, Ratti K, Lee SH, Zheng Y, Takeo M, et al. Hedgehog stimulates hair follicle neogenesis by creating inductive dermis during murine skin wound healing. Nat Commun. 2018 Nov;9(1):4903.

94 Soma T, Dohrmann CE, Hibino T, Raftery LA. Profile of transforming growth factorbeta responses during the murine hair cycle. J Invest Dermatol. 2003 Nov;121(5):969-75.

95 Wang X, Tredget EE, Wu Y. Dynamic signals for hair follicle development and regeneration. Stem Cells Dev. 2012 Jan;21(1):718. 